\title{
Acute peripheral facial paralysis following varicella infection: An uncommon complication
}

\author{
Damla Hanalioğlu${ }^{1}$, Yasemin Özsürekci², Ayşe Büyükçam², Ayşe Gültekingil-Keser ${ }^{1}$, \\ Özlem Tekşam¹, Mehmet Ceyhan² \\ Division of ${ }^{1}$ Pediatric Emergency Medicine and ${ }^{2}$ Pediatric Infectious Diseases, Department of Pediatrics, Hacettepe \\ University Faculty of Medicine, Ankara, Turkey.E-mail: dhanoglu@gmail.com \\ Received: 28th April 2017, Accepted: 31st May 2017
}

SUMMARY: Hanalioğlu D, Özsürekci Y, Büyükçam A, Gültekingil-Keser A, Tekşam Ö, Ceyhan M. Acute peripheral facial paralysis following varicella infection: An uncommon complication. Turk J Pediatr 2018; 60: 99-101.

Chickenpox is caused by varicella zoster virus (VZV/HHV-3), which is one of the eight human herpes viruses. Although chickenpox has a good prognosis, neurologic complications including encephalitis, acute cerebellar ataxia, myelitis and meningitis may seldom be associated with the disease. Peripheral facial palsy (PFP) is an extremely rare complication in patients with chickenpox. Herein, we report a 12 -year-old boy with chickenpox and unilateral peripheral facial palsy, who was successfully treated with shortterm steroids and physical rehabilitation.

Key words: chickenpox, varicella, peripheral facial palsy, pediatric, complication.

Chickenpox also known as varicella, caused by primary infection with varicella zoster virus (VZV/HHV-3) is a highly contagious disease mostly occurring in childhood, and the disease is distributed worldwide. Clinical manifestations generally develop 10-21 days after the exposure resulting in characteristic small, itchy vesicular rash. Typically, the lesions appear to be in different stages of development on the face, the trunk and the extremities. ${ }^{1}$ Although the disease is mild, self-limiting which resolve within several days without treatment, it may rarely lead to severe complications. Bacterial superinfection of blisters on the skin is the most common complication followed by pneumonia. Although quite uncommon $(0.01-0.03 \%$ of the cases), neurologic complications may occur as well. ${ }^{2}$ Most common neurologic complications are encephalitis, acute cerebellar ataxia, myelitis and meningitis. Peripheral facial palsy (PFP) is one of the least common complications of varicella reported to date. ${ }^{3,6}$

Here, we report a 12-year-old boy with unilateral PFP, which developed after chickenpox infection and discuss management strategies.

\section{Case Report}

A 12-year-old male patient presented to the pediatric emergency unit with a 4-day history of drooping of the right corner of the mouth and inability to close the left eyelid. One week prior to his admission to our hospital he had been diagnosed with chickenpox at another center and he did not receive acyclovir. At the same time with the development of PFP, the patient described a transient weakness on his right hand, which had resolved in a few minutes prior to the admission. He denied retroauricular pain, hyperacusis, decreased production of tears, or altered taste. There was no history of previous cold exposure. His past medical history and family history were unremarkable.

On his detailed physical examination on the $7^{\text {th }}$ day after the occurrence of eruption, facial asymmetry was noted due to inability to close the left eye lid and drooping of the right corner of the mouth which was compatible with left sided PFP concomitant with generalized exanthematous scattered rash involving the pinna and external ear canal as well. The tympanic membranes were normal.

Presented at the 9th National Pediatric Infectious Diseases Congress, 2015, Antalya, Turkey. 


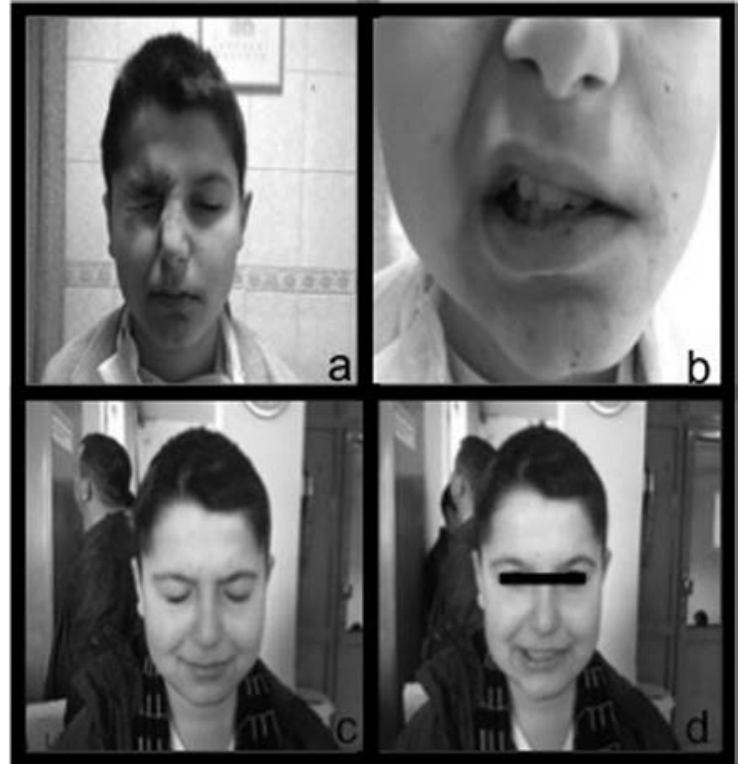

Fig. 1. Pictures taken at the initial admission left-sided PFP $(\mathrm{a}, \mathrm{b})$ and almost complete remission was achieved 2 months later $(\mathrm{c}, \mathrm{d})$. Informed consent was obtained from both the patient and his parents.

Other than PFP, his neurologic examination was unremarkable.

Serologic tests were compatible with acute varicella zoster virus infection. Cranial magnetic resonance imaging (MRI) was normal. The patient was diagnosed with chickenpox complicated with PFP according to physical examination findings and laboratory results. He was treated with prednisolone $50 \mathrm{mg}$ per day for 3 days, then reduced by $10 \mathrm{mg}$ per 3 days for a total treatment period of 15 days, artificial tears, and physical rehabilitation. Almost complete remission was achieved 2 months after his admission to our clinic (Fig. $1)$.

Patient's participation involves patient's and parents' written informed consents.

\section{Discussion}

Chickenpox is a highly contagious disease presenting with a typical exanthematous rash. Chickenpox is mostly diagnosed among children but there is a lifetime risk for those who are not immunized against VZV. The disease is a benign, self-limited condition having a good prognosis. However, some complications including bacterial infection of the skin and soft tissues, pneumonia, encephalitis and rarely neurologic complications may occur. Accounting for only $0.03 \%$ of chickenpox cases, neurologic complications include: encephalitis, acute cerebellar ataxia, myelitis, meningitis and others. Among the neurologic complications, PFP is rarely reported, particularly in childhood. ${ }^{2-5,8}$ Shiihara ${ }^{6}$ reviewed 60 adult and pediatric chickenpox cases with neurological complications in Japanese literature. Encephalitis and cerebellar ataxia were the two leading complications with the rates of $23.3 \%$ and $21.7 \%$, respectively. Facial palsy was reported in $8.3 \%$ of the patients in this study. Bozzola et al. ${ }^{3}$ recently reported that the frequency of neurological complications among immunologically healthy children hospitalized for varicella was $21.7 \%$ in their series, and within the range of $13.9-20.4 \%$ in the literature. Among the patients in their series, $44.7 \%$ had cerebritis. Meningoencephalitis, meningitis and encephalitis were found in $10.5 \%$ of patients. Cranial nerve palsies (not specified) were reported only in four children $(5.2 \%)$ hospitalized for varicella. Our case is one of the very few reported pediatric cases of PFP associated with chickenpox in English literature.

There are two possible underlying mechanisms including viral invasion of nerves or nerve damage due to immunologically mediated inflammatory responses. ${ }^{4}$ We believe that in our patient, VZV within the vesicles on the pinna and ear canal may have invaded the sensory branches of the facial nerve, and at the same time using the neurogenic route the adjacent motor branches may have become inflamed which eventually led to facial palsy.

According to the literature, the period between the appearance of the vesicles of varicella and the facial nerve palsy ranges from five days before existence of eruption and 16 days after the occurrence of eruption. ${ }^{2}$ Consist with the literature, this period was 3 days in our patient after the occurrence of eruption. The palsy may be unilateral or rarely bilateral ${ }^{7}$. It was unilateral in our patient.

Most of the patients were treated with acyclovir and/or steroids along with physical rehabilitation. Adour et al. ${ }^{9}$ compared the final outcome of 99 Bell's palsy patients treated with either acyclovir-prednisone or placeboprednisone in a double-blind study and they concluded that acyclovir-prednisone has better outcomes than prednisone alone when treating Bell's palsy patients due to herpes simplex. ${ }^{9}$ 
However, there is not a definitive management strategy of PFP patients with chickenpox. Therefore, the treatment must be individualized for each patient. We did not use acyclovir because the admission of patient to our center was 7 days after occurrence of eruption; thus, our patient was treated with steroids only and with a good clinical response.

\section{REFERENCES}

1. Adour KK, Ruboyianes JM, Von Doersten PG, et al. Bell's palsy treatment with acyclovir and prednisone compared with prednisone alone: a double-blind, randomized, controlled trial. Ann Otol Rhinol Laryngol 1996; 105: 371-378.

2. Albrecht MA. Clinical features of varicella -zoster virus infection: chickenpox. 2014, http://www.uptodate.com/ online (Search date: 9.5.2015).

3. Bozzola E, Tozzi AE, Bozzola M, et al. Neurological complications of varicella in childhood: case series and a systematic review of the literature. Vaccine 2012; 30: 5785-5790.
4. Ferreira H, Dias A, Lopes A. Acute peripheral facial palsy after chickenpox: A rare association. Case Rep Pediatr 2014; 2014: 754390.

5. Muñoz-Sellart M, Garcial-Vidal C, Martínez-Yelamos S, Niubó J, Fernández-Viladrich P. Peripheral facial palsy after varicella. Report of two cases and review of the literature. Enferm Infecc Microbiol Clin 2010; 28: 504-508.

6. Odemis E, Turkay S, Tunca A, Karadag A. Acute peripheral facial palsy during chickenpox in a child. J Ped Neurol 2004; 2: 245-246.

7. Shiihara H. Neurological complications of varicellazoster virus (VZV) infection. No To Hattatsu 1993; 25: $128-134$.

8. Van der Flier $M$, van Koppenhagen C, Disch FJ, Mauser HW, Bistervels JH, van Diemen-Steenvoorde JA. Bilateral sequential facial palsy during chickenpox. Eur J Pediatr 1999; 158: 807-808.

9. Watanabe Y, Ikeda M, Kukimoto N, Kuga M, Tomita $\mathrm{H}$. A case report of facial nerve palsy associated with chickenpox. J Laryngol Otol 1994; 108: 676-678. 